\title{
Chinese Science Bulletin
}

(c) $2009 \circlearrowleft$ SCIENCE IN CHINA PRESS

Springer

\section{Correction}

The original version of the article titled "Cloning of 9-cis-epoxycarotenoid dioxygenase (NCED) gene encoding a key enzyme during abscisic acid (ABA) biosynthesis and ABA-regulated ethylene production in detached young persimmon calyx", published in 54(16): 2830-2838 (doi: 10.1007/s11434-009-0486-7), unfortunately contained a mistake. The "DKCS2" of Figure 3 and the "Dk-NCED2" of Figure 5 were incorrect.

\section{The original figures:}
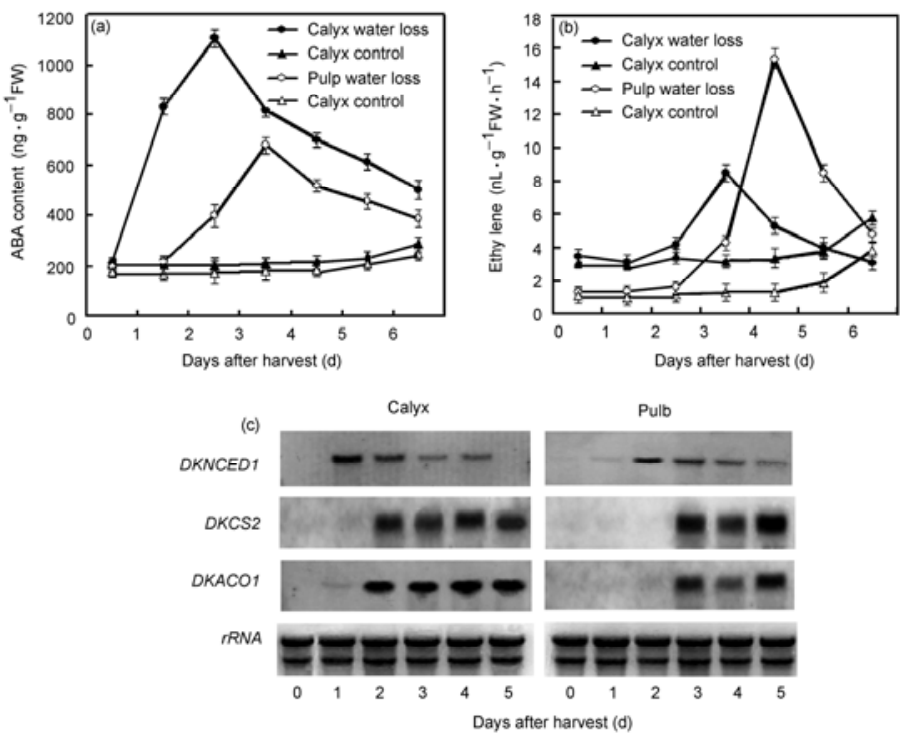

Figure 3

\section{The corrected figures:}
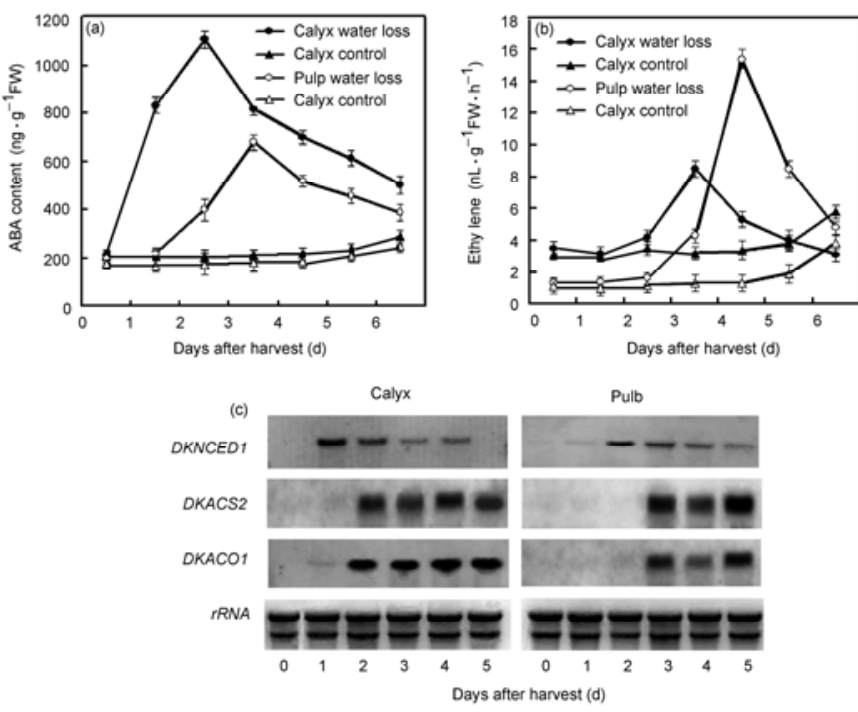

Figure 3

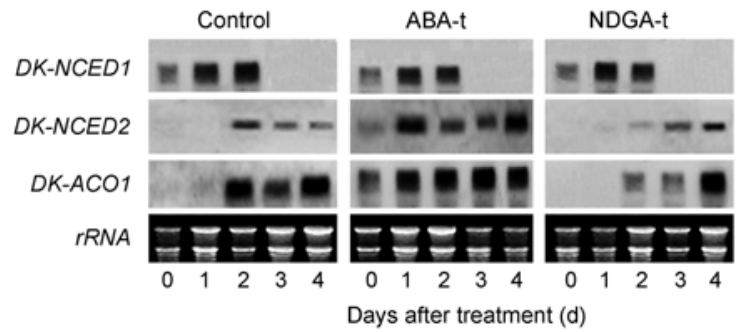

Figure 5

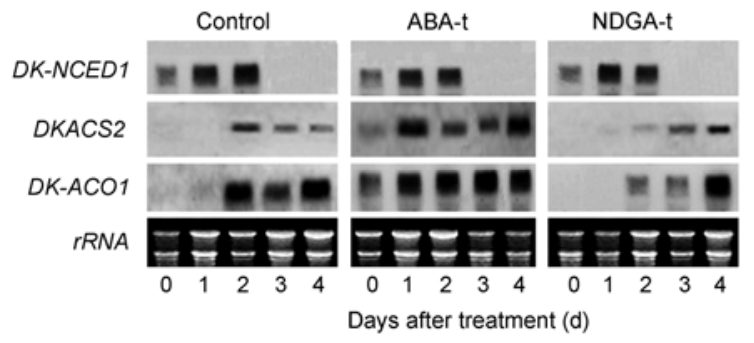

Figure 5

doi: $10.1007 / \mathrm{s} 11434-009-0685-2$ 